\title{
Las llamas de Tapacarí: un documento judicial de un alcalde de indios en la Audiencia de Charcas, $1580^{*}$
}

JEREMY RAVI MUMFORD

Brown University

jeremy_mumford@brown.edu

A principios de 1580, un indígena tributario llamado Martín Pongo presentó una queja ante don Martín Poma, alcalde ordinario de indios. Pongo era un tributario de la encomienda de Tapacarí, mientras que Poma era el alcalde de la reducción de Sipesipe en la encomienda del mismo nombre, ambas ubicadas cerca de la ciudad española de Cochabamba y en contacto cercano con el centro minero de Potosí. Pongo reclamaba que, un año antes, dieciséis llamas ("carneros de cargas») le habían sido robadas cerca de la Villa Imperial de Potosí. Un tiempo después, había encontrado tres en posesión de Esteban Calla, tributario de Sipesipe. Calla respondió que había comprado los animales inocentemente y de buena fe a una tercera persona, un hombre de la provincia de los collas. Pero el alcalde, emitiendo un fallo en contra de un miembro de su propia comunidad, ordenó a Calla que devolviese las tres llamas a Pongo.

* Este texto ha sido traducido por Yukyko Takahashi. Agradezco a Diego Landa por su ayuda en conseguir las imágenes digitales del documento y a Laura Gutiérrez Arbulú por su ayuda invaluable con la transcripción paleográfica.

hISTORIOn XL.2 (2016): 171-185 / ISSN 0252-8894

https://doi.org/10.18800/historica.201602.006 
Un asunto quedaba aún por resolver: ¿qué había de hacerse sobre las otras trece llamas? Calla, habiendo sido encontrado en posesión de parte de la propiedad robada, era legalmente responsable por el total de animales. El alcalde dio a Esteban Calla un año para encontrar al hombre que le había vendido las llamas robadas; de encontrarlo, le podría transferir su responsabilidad. Don Francisco Cañoma, principal del ayllu de Calla, se presentó como su fiador, responsabilizándose por la deuda de Calla en caso de que no lograse encontrar al presunto vendedor o compensar monetariamente a Pongo por la pérdida. La orden del alcalde fue registrada por el escribano de Cabildo Antonio Centeno, quien señaló que don Martín Poma no firmó por no saber hacerlo.

Seis años después, Martín Pongo aún no había sido compensado por su pérdida. Por esta razón, apeló al corregidor español de la villa de Cochabamba. Pongo reclamó una de dos soluciones: que su «administrador» Juan de Villafaña (o Villasaña) colectase el valor de las trece llamas del acusado y su fiador, o que los alcaldes de Sipesipe y Tapacarí se encontrasen en Tapacarí para resolver el caso. El corregidor de Cochabamba ordenó a Calla y Cañoma presentarse ante él. El documento termina aquí.

Estos dos breves documentos, registrados por el escribano de Cabildo de Sipesipe en 1580 y por un escribano público en Cochabamba en 1586, constituyen la totalidad de este expediente, que se encuentra en el Archivo Histórico de Cochabamba. Como ocurre usualmente en el caso de los registros judiciales, este no da cuenta de la sentencia final del caso, aunque sí se refiere a otros documentos no incluidos, como un testimonio de 1580 presentado en la Audiencia ante el alcalde de Sipesipe.

De cierta forma este registro perfila un paisaje familiar. Filas de «carneros de carga» viajaban regularmente entre el valle de Cochabamba y las minas de Potosí, algunas veces acompañando contingentes de mitayos, en ocasiones llevando bienes para la venta. Las encomiendas de Sipesipe y Tapacarí estaban próximas entre sí y eran compartidas por el grupo étnico sora, por lo que no era una sorpresa que un hombre de Tapacarí se enterase de que su propiedad robada estaba en Sipesipe. Al mismo tiempo, también había un tráfico constante entre Potosí y el grupo étnico colla hacia el norte. Si de hecho Calla robó las llamas (y 
dispuso de trece de ellas antes de ser encontrado con las tres últimas), fue lo suficientemente inteligente para alegar que las había comprado de un viajero extranjero. Tal afirmación era plausible, ya que un sora podía cruzarse con collas en Potosí, por lo que la afirmación era difícil de ser probada o refutada. Al juzgar una disputa entre tributarios de Sipesipe y Tapacarí, es notable que el alcalde de Sipesipe fallase a favor de Pongo, tributario de Tapacarí, al menos en el caso de las tres llamas.

También es significativo que Pongo no recibiese más recompensa en los seis años siguientes, a pesar de la promesa del alcalde de hacer a Calla y su fiador responsables por las llamas robadas. Es probable que Pongo recurriese a don Martín Poma después de completarse el primer año, buscando que Calla y Cañoma le retornasen el valor de las llamas perdidas, pero con resultados negativos. Después de todo, desde la perspectiva del alcalde, otorgar tres llamas sanas y salvas era un acto de justicia para un tributario de otra encomienda que había sido víctima de un crimen. Sin embargo, pedirle a un hombre de Sipesipe que pagase a ese extranjero, residente en otro pueblo, el valor de trece llamas _llamas hipotéticas, solamente conocidas por la declaración de los testigos convocados por Pongo- hubiese significado un precio muy alto para la propia comunidad del alcalde. Desde la perspectiva de Pongo, tal era el riesgo de formular una demanda contra alguien ante el propio alcalde del acusado.

La documentación de un fallo judicial de un alcalde de indios en el virreinato del Perú es muy excepcional. Las reformas del virrey Francisco de Toledo, relativas a su Visita General (1569-1575), estuvieron centradas en la creación de una red de pueblos nuevos o reducciones; estas últimas debían ser gobernadas por cabildos diseñados a partir del modelo español con alcaldes, regidores, alguaciles, escribanos y otros oficiales que servirían en un término de un año (con excepción del escribano), pasando la vara de justicia a sus sucesores en el primer día del año nuevo. Los alcaldes fueron oficiales importantes, aún durante las primeras décadas después de la Visita General. Sin embargo, ellos (y aún más los otros miembros del Cabildo de naturales) son difíciles de encontrar en los registros. 
Otra razón para la invisibilidad relativa de los alcaldes es que no eran responsables directamente del tributo y la mita. Estas exacciones eran calculadas en el nivel del repartimiento, asignadas entre los ayllus y recolectadas por el cacique y los principales. En las visitas, revisitas y otras consultas relativas al tributo y la mita — que eran el sustento del gobierno virreinal - los oficiales espańoles interactuaban con los caciques, no con los alcaldes. Similarmente, la tierra y otros bienes de la comunidad se administraban en el nivel del repartimiento y los ayllus, no en el de la reducción. De modo que en las disputas importantes sobre la propiedad, así fuese contra otra comunidad indígena o un español, el portavoz y protagonista era usualmente el cacique, no el alcalde. En un litigio en Achacachi en 1617, por ejemplo, el cacique habla por la comunidad, mientras que el alcalde figura como su intérprete al castellano. ${ }^{1}$ En otros casos, los alcaldes aparecen en los documentos como parte de un grupo indiferenciado de líderes comunitarios, ocultos bajo frases como «los alcaldes y caciques hilacatas e muchos yndios del dicho pueblo». ${ }^{2}$

El mandato del alcalde ordinario era sobre todo de corte judicial, pero tenemos muy poca información acerca de las funciones judiciales de los alcaldes indígenas. Virtualmente no han sobrevivido tales registros de las comunidades indígenas coloniales en los Andes (en contraste con Mesoamérica, donde los municipios indios mantuvieron abundante documentación en lenguas nativas transcritas en el alfabeto latino). Es plausible que, en la mayoría de los casos, a diferencia del de Sipesipe discutido aquí, los procesos judiciales en las reducciones no estuviesen ligados a la escritura.

Había una ambigüedad de base alrededor del alcalde indígena como figura judicial. Por un lado, el establecimiento específico de la institu-

1 «Los indios de Achacache contra Alonso de León, sobre las tierras de Tintilaya y Guacangache». Archivo Nacional de Bolivia, Expedientes Coloniales [en adelante ANB EC], 1617-08, f. 47v. El alcalde de Achacache, descrito como un «indio ladino», figura como intérprete en el testimonio de la segunda persona de Achacache, don Marcos Chambi.

2 «Petición de repartición de tierras en Hilabaya», Larecaja, 1604-1614. Archivo de La Paz, Expedientes Coloniales, 3/23, f. 1. 
ción española del alcalde tenía como propósito la aculturación en las normas cristianas y europeas. Por otro, con el establecimiento de una jurisdicción sólida en la República de Indios, los oficiales espańoles buscaban prevenir que las disputas indígenas alcanzasen jurisdicciones españolas más elevadas (el corregidor y especialmente la Audiencia). En otras palabras, el propósito de los alcaldes indígenas era el de enseñar a los pobladores nativos las normas legales españolas y a la vez excluirlos de los foros legales hispanos.

Esta ambigüedad fue, en cierta medida, inherente al cargo de alcalde, un oficio distintivamente hispánico a través del cual los funcionarios de grandes ciudades y pueblos rurales compartían el mismo título. La ironía de que hombres pobres y humildes reclamaran el título de alcalde era un tropo cómico en la literatura española. El lexicógrafo Sebastián de Covarrubias escribió en 1611: "Hay muchas diferencias de alcaldes; [...] los ínfimos los de las aldeas, los cuales, por ser rústicos, suelen decir algunas simplicidades en lo que proveen, de que tomaron nombre alcaldadass. ${ }^{3}$

El cargo de alcalde, junto con los otros oficios del cabildo, estaba estrechamente relacionado con el programa de urbanismo llamado congregación en Nueva Espańa y reducción en Perú. Hacia 1549, esta era teóricamente la política real en toda Nueva España, Nueva Granada y Perú, aunque fue implementada lenta e inconsistentemente. Las poblaciones indígenas dispersas debían reubicarse en asentamientos nuevos con una organización municipal y jurisdicción legal españolas, con cabildos, plazas y calles rectas, mercados, prisiones y posadas para viajeros. Los oficiales españoles debían persuadir a los indígenas de trasladarse a las nuevas ubicaciones «por la [...] más blanda y amorosa vía». Aun así, el nuevo sistema debía ser obligatorio. ${ }^{4}$

En la Nueva España, desde fechas tempranas, los oficiales españoles y los frailes se mostraron celosos reorganizadores de las comunidades indígenas y los municipios bajo la figura del alcalde. Pero algunos

3 Cervantes 1970; y Covarrubias Orozco 199548.

4 Real cédula, Valladolid, 9 de octubre de 1949, en Málaga Medina 1989: 217-218. Otras cédulas con el mismo texto se despacharon a Nueva Espańa y Nueva Granada. 
observadores españoles creían que esta revolución política y legal en las comunidades indígenas era un error. El jurista Alonso de Zorita escribió, «mejor sería quitar los alcaldes y alguaciles [...] porque no sirven más que de robar y molestar al común y hacerse a holgar y a no tributar». Los nobles tradicionales, en cambio, comprendían a los campesinos indígenas y sus necesidades, pues, bajo el control prehispánico mexica, habían decidido disputas con rapidez y justicia. ${ }^{5}$ Bernardino de Sahagún llegó a la misma conclusión, reclamando que los conquistadores españoles «echaron por tierra todas las costumbres y maneras de regir que tenían estos naturales y quisieron reducirlos a la manera de vivir de España [...] Pero ahora que esta manera de policía cría gente muy viciosa». ${ }^{6}$

Con el tiempo, sin embargo, los cabildos indígenas de Nueva España pasaron a ser dominados por los descendientes de los señores prehispánicos, cumpliendo de cierta manera el deseo de Zorita. La élite indígena creó una síntesis robusta de la tradición prehispánica y las instituciones españolas, como lo demuestran los abundantes documentos municipales escritos en lenguas indígenas con el alfabeto latino.

En Perú, los debates sobre los alcaldes de indios tomaron una forma diferente que en la Nueva España: los alcaldes de indios no eran vistos como el reemplazo de las formas legales tradicionales, sino más bien como su reinstauración. Los oficiales españoles percibían una epidemia de litigiosidad entre la población indígena, en la que todos dirigían sus reclamos y disputas a los jueces españoles. Según la queja típica, los caciques «sal[ia]n con tanta determinación a estos pleitos que [tenían] en poco gastar su hacienda por conseguir cualquiera cosa de muy poco interés». ${ }^{7}$ La solución, según los críticos españoles, era imponer a los litigantes indígenas un sistema legal que sería sumario, sencillo, estricto y justo, sin un procedimiento elaborado ni la necesidad de abogados.

5 Zorita 1993: 39.

6 Sahagún 2011: 71-72.

7 Francisco de Toledo, «Instrucción de los jueces de naturales», La Plata, 20 de diciembre de 1574, en Saravia y Lohmann 1986-1989, I: 462. Sobre la polémica contra la supuesta litigiosidad de los indígenas, véase Honores 2007: 9; Medelius y Puente Luna 2004; y Puente Luna 2014. 
Estas ideas se valieron en parte de una tradición anclada en el Derecho romano, el cual ofrecía un procedimiento simplificado a los «miserables», los pobres e indefensos que no podían navegar en las profundas complejidades de la litigación. ${ }^{8}$ También se basó en la idea de que los sistemas legales prehispánicos (igual que los muchos sistemas no cristianos del Viejo Mundo) eran severos, a menudo crueles, pero sumarios e imparciales. ${ }^{9}$ Pero mientras que la preocupación de Zorita era que los alcaldes indígenas minarían la justicia simple y razonable de los señores tradicionales, lo que las autoridades en Perú deseaban era más bien que los alcaldes pudiesen detener la proliferación de litigios nativos a través de la reinstauración de los principios de la justicia indígena.

En Perú, la idea de los alcaldes indígenas aún parecía una novedad en 1560. En ese ańo, Juan Polo Ondegardo, ejerciendo como corregidor en Cuzco, experimentó con el nombramiento de alcaldes para cada parroquia nativa de la ciudad. El cronista los escogió de entre la aristocracia inca urbana para que decidiesen disputas entre litigantes indígenas basándose en la ley tradicional filtrada a través de los principios cristianos y españoles de derecho, pues aseguraba que dicho sistema había tenido un efecto casi mágico en la resolución de disputas:

$[\mathrm{P}]$ uestos juezes propios y trabajando en tener su capacidad para elegillos y sus constumbres para determinar sus causas, ni era menester juramento ni testigos sino tan solamente la presencia de las partes con la qual de consentimiento y confeszion dellas se determinavan todas las causas que se ofrescían [...] que cierto yo lo tuue por cosa marauilloza. ${ }^{10}$

El énfasis de Polo de Ondegardo en la informalidad y simplicidad procedimental se basó en un discurso tradicional del proceso expedito, para minimizar la complejidad, el retraso y el costo del litigio. Su experimento fue ampliamente visto como exitoso y otros oficiales recomen-

8 Borah 1983: 12-15.

9 Cervantes, por ejemplo, en Don Quijote, parte II, cap. 26, hizo que sus personajes alabasen la rapidez y simplicidad del sistema de justicia morisco, en contraste con los inacabables trámites de la ley castellana (Cervantes 1892, II: 328-342).

${ }^{10}$ Polo de Ondegardo 1940: 129. 
daron su extensión por todo el Perú, para mantener los pleitos nativos fuera de los tribunales. En ese sentido, el doctor Gregorio González de Cuenca escribió:

Una de las cosas de que los yndios mas daño reciben es los pleytos y de tratar con letrados y procuradores y escrivanos que los roban [...] y se tratan en la audiencia con la mesma solennidad y forma de juicio como la de los españoles.

Así, avaló la solución de Polo de Ondegardo de colocar alcaldes de indios para dar justicia sumaria en las disputas entre andinos. ${ }^{11}$

En la década de 1560, el licenciado Lope García de Castro intentó establecer una amplia red de alcaldes indígenas a través de una nueva y ambiciosa campaña de reducciones que fue de la mano con la creación de una nueva y poderosa clase de oficiales reales: los corregidores de indios. Pero este introdujo un requisito que diferenció a los alcaldes indígenas de aquellos escogidos por Polo de Ondegardo en Cuzco: exigió que los nuevos cabildos de las reducciones estuviesen compuestos por tributarios ordinarios y que se mantuviesen fuera de la influencia de los caciques y principales. ${ }^{12}$ A través de la institución simultánea de corregidores de indios españoles y cabildos indígenas, García de Castro esperaba replicar en Perú el fenómeno familiar de la política española en la Península: una alianza entre la autoridad real y el autogobierno local a expensas de los señores. En España, los villorrios campesinos habitualmente solicitaban al rey que los dejase fuera de la jurisdicción aristocrática, en favor de su propio gobierno directo, y que los elevase a la condición de villa o ciudad autónoma; esto significaba, en efecto, confiscar el poder del señor y repartirlo entre el rey y los plebeyos. ${ }^{13}$ En

${ }^{11}$ Gregorio González de Cuenca al rey, Lima, 30 de abril de 1563, en Levillier 1922: 299.

${ }^{12}$ Instrucciones para Nicolás Ruiz de Estrada, corregidor de Chucuito, Lima, 2 de abril de 1565. Archivo General de Indias [en adelante AGI], Justicia 415, N1, R2, ff. 12-13; Instrucciones para corregidores, Lima, 3 de julio de 1565. AGI, Lima 121, expediente suelto, ff. 24r-30v.

${ }^{13}$ Nader 1993. 
Perú, igualmente, el corregidor debía seleccionar a los oficiales andinos municipales entre los indios del común, no entre los caciques. Al emancipar a los andinos de sus caciques, García de Castro se vio a sí mismo como su héroe, ofreciéndoles un autogobierno en el sentido más real, a la vez que fortalecía el poder del rey.

Los historiadores dudan de cuántas reducciones y cabildos fueron establecidos bajo el gobierno de García de Castro, pero parece que su impacto no tuvo mucha extensión. Sin embargo, en los lugares donde fueron establecidos, su intento de aislar a los cabildos de la influencia del cacique falló. En el valle del Mantaro, por ejemplo, los caciques y sus parientes se hicieron alcaldes y regidores, tratando las nuevas instituciones no como amenazas, sino como vehículos para sus propias ambiciones. Esto no es sorprendente, pues en la propia España los nobles y oligarcas tendían a controlar las instituciones otrora populares de autogobierno municipal. Los miembros de un cabildo indígena del valle del Mantaro solicitaron al rey que les fuesen concedidos los privilegios y honores que los regidores ostentaban en Espańa, incluyendo mantener su cargo a perpetuidad y ser investidos como "cavalleros». ${ }^{14}$ Además, los cabildos, controlados por los caciques, preservaban las tradiciones prehispánicas, como los festivales ritualizados en las plazas de las nuevas reducciones. Según la queja de un corregidor, los indígenas en su corregimiento pasaban los días «beviendo con los caciques y principales en la plaça donde hazen todos los dias del mundo cavildo». ${ }^{15}$

El paso decisivo en el establecimiento de los cabildos indígenas, al menos en las Audiencias de Lima y Charcas, fue la Visita General del virrey Francisco de Toledo (1569-1575). Uno de los objetivos centrales de la Visita fue el reasentamiento de la totalidad de la población indígena en reducciones. Las instrucciones de Toledo establecieron que las reducciones debían ser, en la medida de lo posible, idénticas entre sí. Ellas tendrían un trazado en forma de damero con calles rectas y una

${ }^{14}$ Cabildo de Chongos al rey, 8 de enero de 1566 [erróneamente fechado 1565]. AGI, Lima 121, ff. 57-58.

${ }^{15}$ Francisco de Balboa a Castro, 12 de enero de 1566. AGI, Lima 121, f. 53. 
plaza cuadrada en donde se construirían la iglesia, el ayuntamiento, la prisión y las casas del cura párroco y el carcelero. ${ }^{16}$

El Cabildo de la reducción constaba de dos alcaldes, cuatro regidores, un alguacil y varios oficiales menores. Los alcaldes podían oír disputas en el Concejo y visitar la prisión una vez por semana. Tal como en una villa española, el día de año nuevo se llevaba a cabo una ceremonia formal en donde los alcaldes entregaban sus varas ceremoniales de investidura a sus reemplazos. Los caciques y principales eran vetados de los cargos municipales (a excepción de un alcalde, que podía ser un principal) y también de influenciar en su selección. Los alcaldes y regidores escogían a su propio sucesor cada año, quien a su vez elegía a los oficiales de inferior rango. ${ }^{17}$

A pesar de la intención de escoger a los nuevos alcaldes entre el común de los pueblos, muchos alcaldes eran familiares de los caciques y principales. Este parece haber sido el caso en Sipesipe. Varios documentos desde 1560 hasta 1573 nombran a don Martín Poma como uno de los cuatro caciques de Sipesipe. ${ }^{18}$ Un documento de 1560 estima su edad en 30 años, por lo que es posible que el alcalde de 1580 sea el mismo individuo, a pesar de la prohibición. No habría sido el único caso en el que un alcalde también fuese cacique. El cacique Poma, por otro lado, parece haber muerto antes de 1581, pues su nombre no figura en una lista de los caciques de Sipesipe. ${ }^{19}$ Probablemente el alcalde Poma de 1580 fuera hijo o pariente del cacique del mismo nombre.

El alcalde don Martín Poma dio una sentencia admirablemente imparcial en la disputa de 1580, favoreciendo los intereses del tributario de Tapacarí y no los de su propio paisano de Sipesipe. Pero, aparentemente,

\footnotetext{
${ }^{16}$ Mumford 2012.

17 «Instrucciones para los visitadores», Lima, sin fecha [1569-1570] (Sarabia Viejo 19861989, I: 1-39); y "Ordenanzas para la vida común en los pueblos de indios», Arequipa, 6 de noviembre de 1575 (Ib., II: 217-266).

${ }^{18}$ Archivo Histórico de Cochabamba, Expedientes Coloniales [en adelante AHC EC] 22, f 450v; AHC EC 16, ff. 444-469; AHC EC 17, f. 823r; AHC EC 16, f. 300r; AHC EC 16, f. 9r; AHC EC 27, f. 375r.

${ }^{19}$ Los carangas de Colquemarca sobre tierras de Colcapirua. AHC EC 33, f. 15 r.
} 
no hizo cumplir la sentencia, lo que llevó al demandante a apelar al corregidor de Cochabamba. Esto plantea la pregunta obvia de cómo un conflicto entre los litigantes de diferentes pueblos podría ser justamente juzgado por el alcalde de uno de ellos. En el ejemplo dado por José Carlos de la Puente y Renzo Honores en este número, la respuesta era que los dos alcaldes decidiesen el caso en conjunto. Y este fue uno de los dos remedios que Pongo solicitó en 1586.

Si esto ocurrió, la colaboración entre los dos alcaldes podría haber sido facilitada por la estrecha relación entre los dos repartimientos. Según testigos en un caso de 1575, los tributarios de Tapacarí visitaban Sipesipe cada año para sembrar las chácaras que poseían cerca de él y, algunas veces, se quedaron en el pueblo. ${ }^{20}$

La preferencia de Martín Pongo, sin embargo, era que Mendoza decidiese el caso en su favor, remitiendo una orden al administrador de Tapacarí, Juan de Villafaña, para que hiciera que se le remunerase por las trece llamas desaparecidas. Tapacarí, al igual que los otros repartimientos en el corregimiento de Cochabamba, tenía un administrador de bienes designado para controlar su propiedad comunitaria. Es de suponer que, en este escenario, Villafaña le pagaría a Pongo desde la caja de comunidad de su propio repartimiento, Tapacarí, para luego cobrar la deuda del ayllu de Esteban Calla en Sipesipe. ${ }^{21}$

20 «Este testigo suele venyr cada ańo de Tapacarí de donde es natural a senbrar a este valle por este pueblo de Sipesipe[;] algunas vezes a dormido en el y otras vezes en algunas chacaras de yndios deste pueblo». AHC EC 16, f. 52.

${ }^{21}$ En la Visita General, el virrey Toledo nombró funcionarios salariados con el título de administrador de bienes, para gestionar la propiedad comunitaria de repartimientos. Este oficio ha sido poco estudiado. En Lucanas, como muestra De la Puente Luna, los administradores eran indígenas - de hecho, miembros de familias cacicales importantes-y estaban estrechamente involucrados en la vida de la comunidad. Pero en algunos otros lugares los administradores eran españoles. En provincias como Jauja y Chucuito, los caciques hicieron esfuerzos para remover a estos funcionarios (Puente Luna 2008: 15 y 2014: 44-45). En Paria, cerca de Cochabamba, el español nombrado administrador de los hospitales y comunidades de Paria ejercía poderes similares a los de un corregidor de indios. Todos los nombres de los administradores de bienes en la región de Cochabamba son españoles, como Juan de Villafańa, aunque no es imposible que algunos fueran indígenas. 
¿Por qué documentos como este son tan raros? Los pueblos indígenas fueron obligados por ley a tener escribanos de Cabildo, y había muchos indígenas alfabetizados (el escribano de Cabildo de Sipesipe, Antonio Centeno, a pesar de su nombre español, era un hombre indígena). ${ }^{22} \mathrm{La}$ ley era ambigua en cuanto a si los escribanos debían llevar un registro escrito de los procedimientos ante los alcaldes de indios. Este documento, por supuesto, sobrevive porque la disputa involucraba a dos comunidades diferentes y fue llevado al tribunal superior del corregidor de Cochabamba. Debe haber habido muchos documentos similares que se perdieron o fueron abandonados, o se conservan hasta hoy en los archivos privados de los municipios campesinos.

Aun así, puede haber algo inusual en este caso. Sipesipe era una encomienda de la Corona, muy cercana a la ciudad de Cochabamba. En 1572, durante la Visita General, el visitador nombró un protector que inició una serie de demandas contra otras comunidades indígenas, así como individuos españoles, para recuperar tierras. Al juzgar las controversias, según los españoles del valle, el visitador mostró un claro sesgo a favor de Sipesipe, en donde tenía su tribunal en lugar de Cochabamba, con el gran inconveniente que dicha ubicación significaba para los litigantes españoles. ${ }^{23}$ Es posible que este ejemplo directo del procedimiento judicial formal, no en la ciudad sino en la propia reducción, estableciera el precedente de mantener registros escritos de los pleitos y fallos, los cuales podrían haber sido conducidos y alcanzados sin escribir en muchos otros pueblos indígenas.

22 Un documento de 1583 identifica el escribano de cabildo de Sipesipe como Diego Centeno, indio ladino; probablemente es la misma persona. "Juicio seguido por Juan Duran contra los caciques de Sipesipe, sobre las tierras de Icallunga (Yungas), año 1584». ANB EC 1584-04, f. 68r.

23 "Juan Flores contra los caciques de Sipesipe sobre tierras de Tacona». AHC EC 16, f. 224 r. 


\section{BIBLIOGRAFÍA}

Borah, Woodrow Wilson. 1983. Justice by Insurance: The General Indian Court of Colonial Mexico and the Legal Aides of the Half-Real. Berkeley: University of California Press.

Cervantes, Miguel de. 1892. El ingenioso hidalgo don Quijote de la Mancha. Edición de Luis Tasso y Serra. Barcelona: Luis Tasso.

Cervantes, Miguel de. 1970. «La elección de los alcaldes de Daganzo». En Entremeses. Edición, introducción y notas de Eugenio Asensio. Madrid: Castalia, pp. 103-126.

Covarrubias Orozco, Sebastián de. 1995. Tesoro de la lengua castellana o española. Edición de Felipe C.R. Maldonado y Manuel Camarero. Madrid: Castalia.

Honores, Renzo. 2007. Una sociedad legalista: Abogados, procuradores de causas y la creación de una cultura legal colonial en Lima y Potosí, 1540-1670. Tesis de doctorado. Florida International University.

Levillier, Roberto (ed.). 1922. Audiencia de Lima. Correspondencia de presidentes y oidores, 1549 - 1564. Madrid: Biblioteca del Congreso Argentino.

Málaga Medina, Alejandro. 1989. Reducciones toledanas en Arequipa (pueblos tradicionales). Arequipa: Universidad Nacional de San Agustín.

Medelius, Mónica y José Carlos de la Puente Luna. 2004. "Curacas, bienes y quipus en un documento toledano (Jauja, 1570)». Histórica. Vol. 28, núm. 2: 35-82.

Mumford, Jeremy Ravi. 2012. Vertical Empire: The General Resettlement of Indians in the Colonial Andes. Duke: Duke University Press. https://doi. org/10.1215/9780822395591

Nader, Helen. 1993. Liberty in Absolutist Spain: The Habsburg Sale of Towns, 15161700. Londres: The Johns Hopkins University Press.

Puente Luna, José Carlos de la. 2008. «Felipe Guaman Poma de Ayala, administrador de bienes de comunidad». Revista Andina. Vol. 47: 9-51.

Puente Luna, José Carlos de la. 2014. «That Which Belongs to All: Khipus, Community, and Indigenous Legal Activism in the Early Colonial Andes». The Americas. Vol. 72, núm. 1: 19-54. https://doi.org/10.1017/tam.2014.4

Polo de Ondegardo, Juan. 1940. «Informe del licenciado Juan Polo de Ondegardo al Licenciado Briviesca de Muñatones sobre la perpetuidad de las encomiendas en el Perú». Revista Histórica. Vol. 13:125-196.

Sahagún, Bernardino de. 2011. Historia general de las cosas de Nueva España. Edición de Carlos María de Bustamante. Cambridge: Cambridge University Press. https://doi.org/10.1017/cbo9780511792892

Sarabia Viejo, María Justina. 1986-1989. Francisco de Toledo: disposiciones gubernativas para el Virreinato del Perú. Sevilla: Escuela de Estudios Hispanoamericanos y Consejo Superior de Investigaciones Científicas, 2 vols.

Zorita, Alonso de. 1993. Los señores de la Nueva España. México, D. F.: Universidad Nacional Autónoma de México. 


\section{Apéndice}

Causa ejecutiva seguida por Martín Pongo del pueblo de Santiago de Hurmiri (Tapacari) contra Esteban Calla de Sipe Sipe y Francisco Cañoma (1580-1586)

\section{[f.445r] 1586}

Martín Pongo de Hurmyre contra Estevan Calla y don Francisco Canoma. Juez el señor corregidor. $[E]$ scrivano Cristoval Perez Navarrete.

[f. 446r] En el pueblo de san Pedro de Talavera de Sipesipe a veynte seys días del mes de febrero de mil e quinientos e ochenta años ante el muy magnífico señor don Martín Poma alcalde ordinario del dicho pueblo y por ante mí Antonio Centeno escrivano de cavildo del dicho pueblo averig $[u]$ o el dicho señor alcalde el pleyto que fue entre Estevan Calla yndio del aillo Guayllamo y Martín Pongo del pueblo de Tapacarí aviendo dado querella el dicho Martín Pongo de que avía hurtado diez y seys carneros junto la villa de [testado: oropessa] ynperial de Potosí y avía paresido tres carneros en poder del dicho Estevan Calla y el dicho señor alcalde mandó que se la buelva y bolvió los dichos tres carneros y el dicho Estevan Calla pedió al dicho señor alcalde que de lugar a que buscara al yndio que le vendió declara quel dicho conpró quatro carneros de los yndios collas como paresió por un testigo que presentó el dicho Martín Calla $[s i c]$ y syn embargo de lo que dixo mandó bolver los dichos tres carneros y por fiador de que quede inconcluso el dicho pleyto dio a don Francisco Cañoma y ansí lo mandó y prove[y]ó y no firmó porque no supo.

ante mí

Antonio Centeno [rubricado]

[e]scrivano de cavildo

[f. 447r] [Al margen:] 3 disiembre 86.

seńor corregidor

muy ylustre señor

en la villa de Oropesa tres días del mes de diciembre de mil y quinientos y ochenta y seis años antel ilustre señor capitán Juan de Mendoça corregidor y justicia mayor y juez de naturales en ella y su jurisdición por su magestad e presentó el contenido con el testimonio que en ella [se hiso en puçision?].

Martín Pongo yndio del pueblo de Santiago de Hurmiri parezco ante vuestra merced y digo que un yndio del pueblo de Sipesipe llamado Estevan Calla se me hurtó dezisiés[sic] carneros de cargas junto a la villa ymperial de Potosí 
abrá como [testado: seis] [entre renglones: siete] años poco más o menos que se me hur[taron]y así los tres carneros de los dichos pareçió en el poder de Estevan Calla cabo de un año desde que se me perdió los dichos dezesiés [sic] carneros los quales [testado: ha] tres carneros hallé en el pueblo de Sipesipe del en poder del dicho yndio luego como hallé di querella al alcalde de Sipesipe que era entonçes que se llamava don Martín Poma el qual se averiguó como y de quien uvo los dichos tres carneros y respondió el dicho Estevan Calla ladrón deziendo que se comprava de un yndio colla negándose el hurto que hazía y pedió al alcalde que le diese licencia para [testado: que] boscar el yndio que vendió y no se ahallado [sic] hasta agora [testado: demas el] [entre renglones: a mas] tienpo de seis años a esta parte y para boscar al yndio que se les vendió dio un fiador que es su prinçipal que se llama don Francisco Cañoma. Por tanto a vuestra merced suplico y pido sea servido de mandarme dar un mandamiento remetiendo a mi adminestrador Juan de Villafaña para quese me haga pagar [entre renglones: los treze carneros] o a los dos alcaldes uno de Sepisipe [sic] y otro de Tapacarí que se hagan justicia en el pueblo de Tapacarí atento a que soy pobre no tengo con qui sustentar a mi muger e hijos que en ello resbiré [sic] bien y merced con justicia etc. pido justiçia y lo más neçesario.

Martín Pongo [rubricado].

Otrosí digo hago presentación de la carta que el alcalde me mandó dar sobre el fiador que salió del dicho Estevan Calla sobre los treze carneros que es su propio prinçipal llamado don Francisco Cañoma [447v] E visto por el dicho señor corregidor el dicho [¿escrito?] e petición de atrás que mandó se despache e que parezcan ante su merçed el dicho en razón alguna era derecho el dicho Martín Calla y don Francisco Canoma su fiador y pareçedes en anbas partes para proveer e justicia así lo proveyó y mandó e señaló Martín de Mendoça ante mí Christóval Perez Navarrete [rubricado] [e]scrivano público. Archivo Histórico de Cochabamba, Expedientes Coloniales 12, ff. 445-447. 